\title{
Guided tissue regeneration: a review
}

\begin{abstract}
The concept that only fibroblasts from the periodontal ligament or undifferentiated mesenchymal cells have the potential to re-create the original periodontal attachment has been long recognized. Based on this concept, guided tissue regeneration has been applied with variable success to regenerate periodontal defects.
\end{abstract}

Keywords: guided tissue regeneration, periodontal regeneration, membranes, infrabony pockets
Volume 6 Issue 3 - 2017

\author{
Smitha Annie Jacob, ' Amudha $D^{2}$ \\ 'Department of Prosthodontics and Implantology, Syamala \\ Reddy Dental College Hospital \& Research Centre, India \\ ${ }^{2}$ Department of Periodontics, N.S.V.K Sri Venkateshwara Dental \\ College and Hospital, India
}

\begin{abstract}
Correspondence: Smitha Annie Jacob, Department of Prosthodontics and Implantology, Syamala Reddy Dental College Hospital \& Research Centre, Marathahalli, Bangalore, Karnataka, India, Email dr.smitha.jacob@gmail.com
\end{abstract}

Received: September 02, 2016 | Published: February 08, 2017

\section{Introduction}

The human body's ability to repair both hard and soft tissue is a natural biologic phenomenon. Within biologic limits, most tissue will repair itself. Regeneration, however, is another matter, in the majority of cases where tissue loss has occurred, the tissue is incapable of restoring itself to its previous condition. The loss of tissue may be the result of birth defects, disease, trauma, malignancies, atrophy, or surgical excision. Replacement of lost body parts has always been a concern to both the patient and the clinician.

The objective of tissue replacement is to recreate or regenerate the loss or damaged structure and to mimic as closely as possible the original form and function. The grafting material should be biocompatible to the host receiving the graft at the hard and soft tissue interfaces. ${ }^{1}$ The host tissue has a potential for damage and rejection of the graft. The clinician must determine the objective of the grafting material and the procedure for its application. The result will be determined by the classification of material used and the technique of the procedure. Regeneration is classified into guided bone regeneration (GBR) or guided tissue regeneration (GTR). Guided bone regeneration refers to an edentulous area, whereas Guided tissue regeneration refers to the regeneration of bone, periodontal ligament, and cementum around teeth. This article deals with the concept of Guided bone regeneration (GBR) and its applications.

\section{Discussion}

\section{Definition}

Guided tissue regeneration, as defined in the Glossary of Periodontal Terms (4th Edition), also has guided bone regeneration included in its definition as follows: "Procedures attempting to regenerate lost periodontal structures through differential tissue responses. Guided bone regeneration typically refers to ridge augmentation or bone regenerative procedures; guided tissue regeneration typically refers to regeneration of periodontal attachment. Barrier techniques, using materials such as expanded polytetrafluoroethylene, polyglactin, polylactic acid, calcium sulfate, and collagen, are employed in the hope of excluding epithelium and the gingival corium from the root or existing bone surface in the belief that they interfere with regeneration." Both of these concepts are under the umbrella term of regeneration, which in itself is defined as, "reproduction or reconstruction of a lost or injured part."

\section{Goal}

The goal of membrane barrier procedures is to guide proliferation of the different tissues during healing after therapy (selective cell repopulation). ${ }^{2}$ Cells that have the capability to form bone, cementum and periodontal ligament must occupy the defect to stimulate regeneration of the tissues. The progenitor cells reside in the periodontal ligament or alveolar bone or both, which remain around the tooth or bony defect. Placement of a physical barrier between the gingival flap and the defect before flap repositioning and suturing prevents gingival epithelium and connective tissue (undesirable cells) from contacting the space created by the barrier. It also facilitates repopulation of the defect by regenerative cells. ${ }^{3}$

\section{Advantages ${ }^{4}$}

Membrane barrier techniques or osteopromotion procedures use a barrier to prevent other tissues, especially connective tissue, from entering the intended site of bone reformation and from interfering with osteogenesis and direct bone formation.

a. Membranes may also provide additional wound coverage, acting as a duplicate surgical flap to provide added stability and protection of the blood clot and they prevent ruptures along the interface between the healing tissues and the root surface.

b. In addition, membranes may also provide a tent-like area for the blood clot, creating a space under the surgical flap that will act as the scaffold for in-growth of cells and blood vessels from the base of the lesion.

c. Creating and maintaining a blood clot-filled space, preventing inflammation as a result of bacterial invasion, isolating the 
regenerative space from undesirable tissues and ensuring mechanical stability of the resolving wound complex are some of the most important factors for creating a suitable environment for regeneration.

\section{Materials used for membrane barrier techniques ${ }^{5-8}$}

Different types of membrane materials have been developed concomitant with expansion of the concept of membrane barrier techniques, and their clinical applications.

\section{Non-resorbable membranes}

a. Cellulose filters

b. Expanded polytetrafluoroethylene membranes

\section{Resorbable materials and devices}

a. Collagen membranes

b. Polylactic acid

c. Polyglycolic acid and polylactic acid

d. Synthetic liquid polymer Polyglactin

e. Calcium sulfate

f. Acellular dermal allografts

g. Oxidized cellulose mesh

\section{Non-resorbable membranes}

The first few studies used non-resorbable materials such as cellulose filters ((Millipore filter, Milllpore Corp...Bedford, MA) and Expanded polytetrafluoroethylene (ePTFE) (Gore-Tex material, W. L. Gore and Associates, Inc...Flagstaff, AZ). These materials were not originally manufactured foruse in medical or dental procedures. Cellulose filters and ePTFE were chosen as barrier materials because they allowed the passage of liquid and nutritional products through the barrier, but their microporosity excluded cell passage., ${ }^{910}$

Cellulose filters: Nyman and others conducted the initial studies of the use of cellulose filters in primates to exclude connective tissue and gingival epithelium, allowing cells fromthe periodontal ligament to repopulate the wound. The periodontal ligament cementum and alveolar bone on the facial aspect of the cuspid teeth were removed and cellulose filters were placed over the defects. Histologic examination showed regeneration of the alveolar bone and new attachment of new cementum with inserting periodontal ligament fibers.

Disadvantages: include exfoliation, premature removal, and the need for a second surgical procedure for their removal.

\section{Expanded polytetrafluoroethylene membranes}

Membranes made of ePTFE are composed of a matrix of polytetrafluoroethylene (PTFE) nodes and fibrils in a microstructure that vary in porosity, which addresses the clinical and biologic requirements of its intended applications. ePTFE is recognized for its inertness and tissue compatibility. The porous microstructures allow the in-growth and attachment of connective tissue for stabilization of the healing wound complex and Inhibition of epithelial migration. ${ }^{11}$ In addition, this material has a history of safe and effective use as implantable medical material (Figure 1A-1D). These membrane barriers consist of two parts. ${ }^{12,13}$

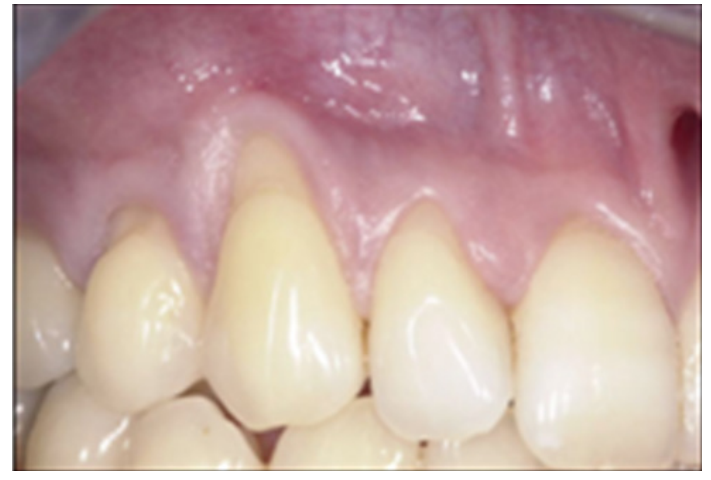

Figure IA Multiple adjacent Class I recession.

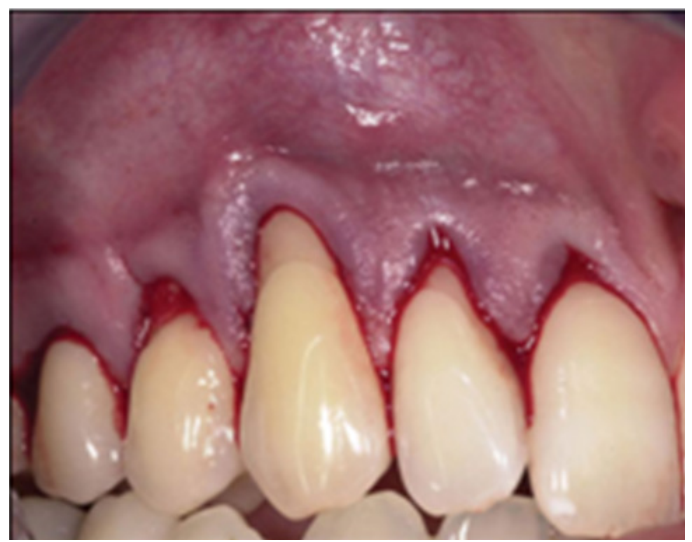

Figure I B Intracrevicular incision extended beyond the mucogingival junction.

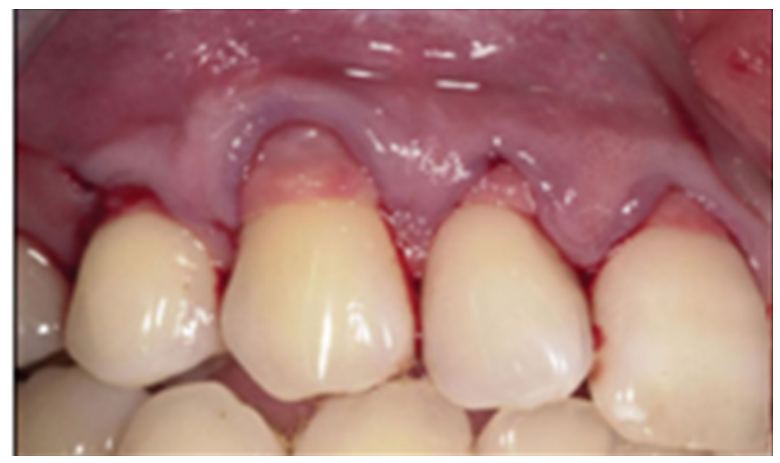

Figure IC Graft application.

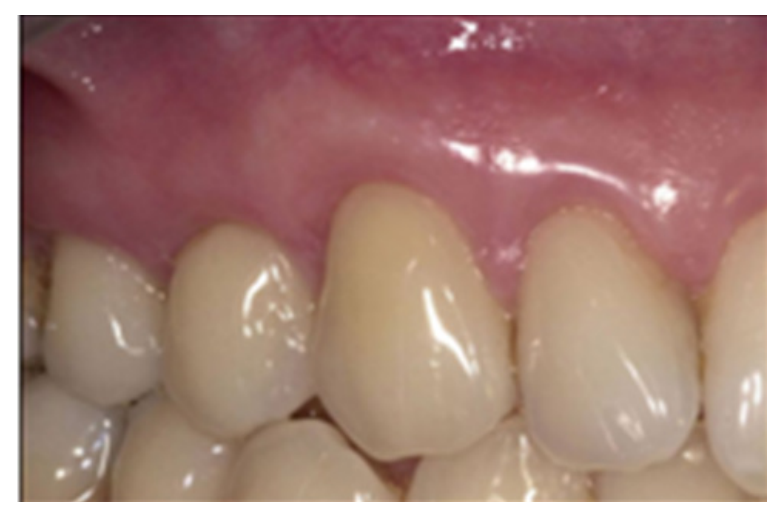

Figure ID Healing 12 weeks after surgery. 
a. The first part is a coronal border (open microstructure collar) that facilitates early clot formation and collagen fiber penetration to stabilize the membrane into place. The collar may also stop apical proliferation of epithelium through a phenomenon called contact inhibition.

b. The second part is an occlusive portion that prevents gingival tissues outside the barrier from interfering with the healing process at the defect site. There are two configurations of ePTFE membranes, transgingival and submerged, that can be used in different situations.

c. The transgingival design is used to treat defects that are associated with structures that extend through the gingiva such as teeth.

d. The submerged design is used in situations where there is no communication with the oral environment, such as bony defect.

Titanium-reinforced ePTFE membranes: were designed to increase the tent like effect, which is an advantage when the defect morphology does not create an adequate space. The creation and maintenance of a space have been recognized as important requirements for achieving regeneration. Space making is dependent on the mechanical ability of a membrane to resist collapse as well. However, these membranes had some degree of memory which limited their use to situations in which adequate support of the membrane would be provided by the adjacent bone. Therefore, titanium-reinforced ePTFE membranes (Figure 2) were created to be used in situations where the anatomy of the defect may cause non reinforced material to collapse into the defect space or where more space is needed for the desired regeneration. Titanium reinforced membranes are available in transgingival and submerged configurations as well. ${ }^{14,15}$

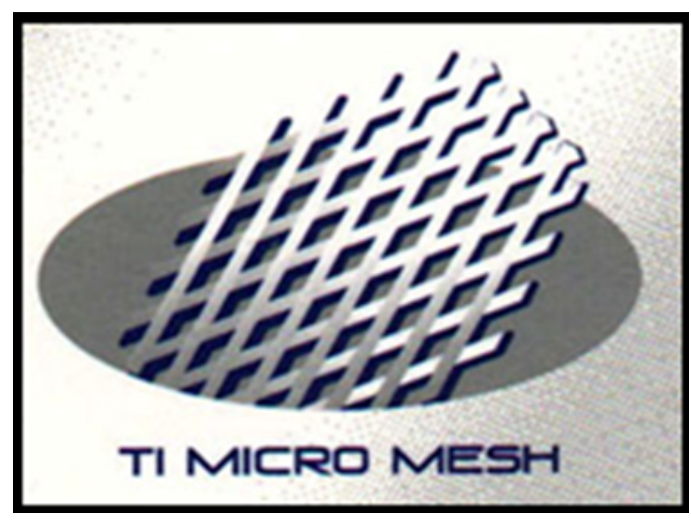

Figure 2 Titanium-reinforced ePTFE membranes.

Advantage: is that the membrane retains its functional characteristics long enough for adequate healing to occur, and then it can be eliminated immediately. After removal, there is no possibility of breakdown products interfering with the maturation of the regenerated tissues.

Disadvantage: of the use of ePTFE membranes is that a second surgical procedure is required for their removal, which increases the cost and surgical trauma to the patient.

\section{Resorbable materials and devices}

Advantage: The avoidance of a second surgical procedure, which reduces patient morbidity and expense.
Disadvantages: of using bioresorbable membranes is that material exposure or flap dehiscence can cause postoperative tissue management problems. Material exposure after surgery can lead to bacterial growth, alteration of fibroblast morphology, and migration, all of which may jeopardize the success of the regeneration process. Another common problem is the difficulty in preventing membrane collapse into the defect, which can result in inadequate space making. ${ }^{16}$

Collagen membranes: Collagen is a physiologically metabolized macromolecule of the periodontal connective tissue that has two different properties: chemotactic (for fibroblasts) and hemostatic (Figure 3). This material is also a weak immunogen and may act as a scaffold for migrating cells. Collagen possesses several characteristics that make it suitable barrier material, including favourable effects on coagulation and wound healing. Controlled cross-linking.${ }^{17}$ Low antigenicity and extensibility, high tensile strength and fibre orientation. Collagen can also be produced in various forms (e.g., sheets, gels, tubes, powders, sponges).

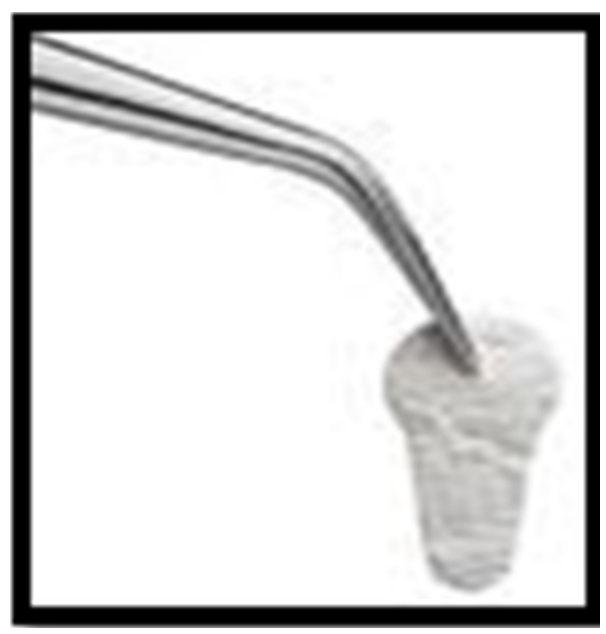

Figure 3 Collagen membrane.

\section{Advantages of the use of collagen membranes}

a. Minimal postoperative complications

b. A good healing rate and no incidence of material dehiscence

c. Tissue perforation

d. Sensitivity

e. Immune response

f. Tissue sloughing

g. Delayed healing or postoperative infection

Polylactic acid: A bioresorbable matrix barrier composed of a blend of polylactic acid that was softened with citric acid for malleability and to facilitate clinical handling (Guidor) was first resorbable barrier to be approved by the Food and Drug Administration (FDA) for membrane barrier techniques. This device is a multilayered matrix that is designed for in-growth of connective tissue, preventing apical down growth of gingival epithelium. The layer that is in contact with the bone or tooth (the inner layer) features small circular perforations and several space holders to ensure enough room for the formation of new attachment, whereas the layer in contact with the gingival tissue 
(the outer layer) has larger rectangular perforations to allow rapid ingrowth of gingival tissue into the interspace between the two layers, preventing or minimizing epithelial down growth (Figure 4A-4D). The resorption process of the material is programmed to ensure barrier function for a minimum of 6 weeks, after which it slowly resorbs. Complete resorption occurs at approximately 12 months. ${ }^{18}$

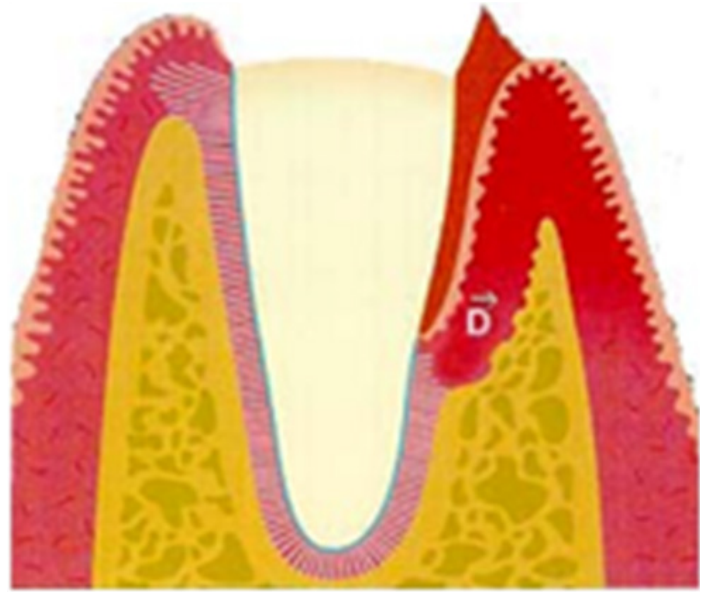

Figure 4A Step I - Diseased gum pocket and bone defect (D).

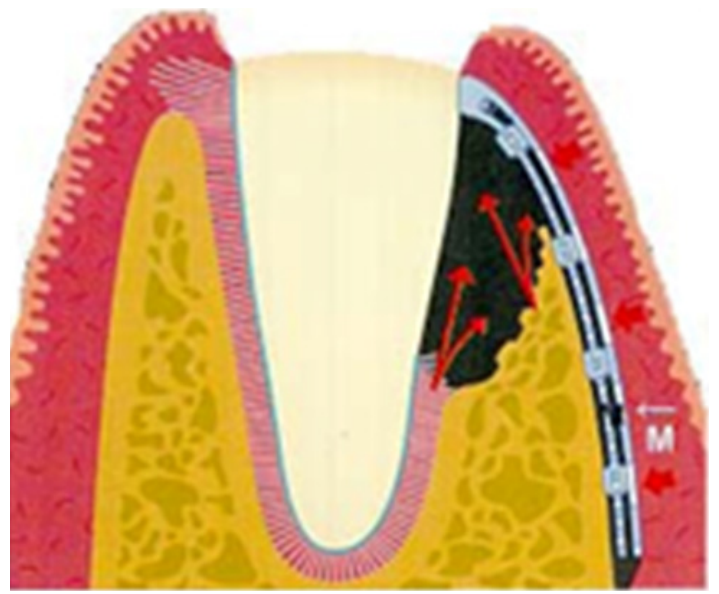

Figure 4B Step 2 - Placement of the Polylactic acid membrane (M) during surgical therapy.

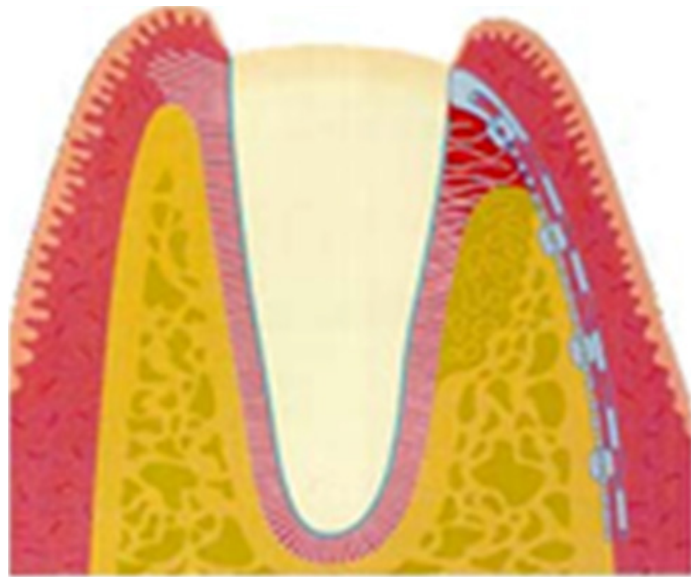

Figure 4C Step 3 - Bone regeneration and Integration.

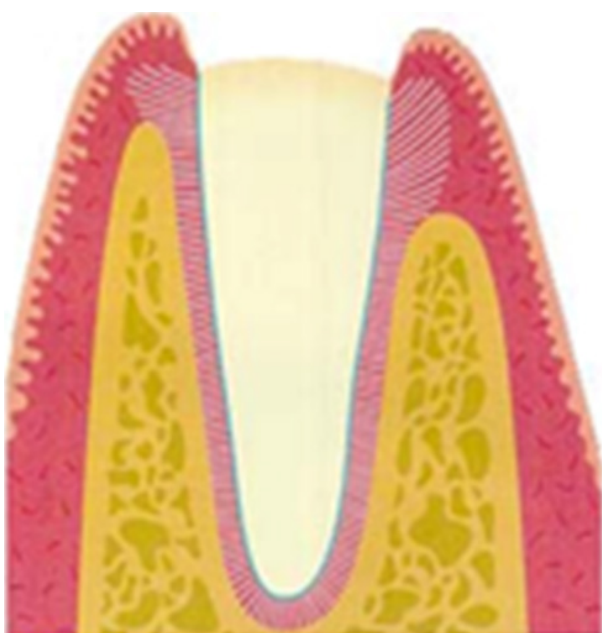

Figure 4D Step 4 - Restoration of health.

Polyglycolic acid and polylactic acid: Bioresorbable membranes made of polyglycolic acid (Figure 5) and polylactic acid (Resolut, W. L. Gore. Flagstaff. AZ) have been tested in experimental animals and proven to be safe with a minimal inflammatory response and promotion of periodontal regeneration. These membranes consist of an occlusive film with a bonded, randomly oriented, fibre matrix located on each surface. The film bonds the fibres and separates the soft tissue from the defect. The random arrangement of the fibres and the openness of the fibrous matrix encourage the in-growth of connective tissue and inhibit apical migration of the epithelium. ${ }^{19}$ The fibre matrix is the primary structural component that provides adequate strength for space making during the initial phases of healing ( 2 to 4 weeks for periodontal defects)

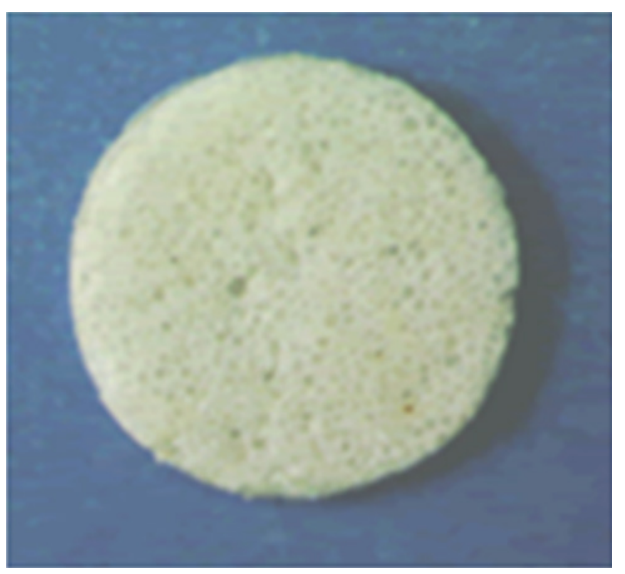

Figure 5 Polyglycolic acid membrane.

Synthetic liquid polymer (Atrisorb): A polymer of lactic acid, poly (DL-lactide) (PLA), dissolved in N-methyl-2-pyrrolidone (NMP) has been studied as a resorbable barrier material. The material begins as a solution that sets to a firm consistency on contact with water or other aqueous solution (Atrisorb, Block Drug Corporation. Jersey City, NJ). The polymer composition is similar to that of Vicryl sutures (Ethicon Inc). When outside the oral cavity, the membrane is a partially set solution which allows it to be trimmed to the dimensions of the defect before intraoral placement. The barrier is then adapted to the defect and sets in a firm consistency in situ. Because of its semi rigid property 
in the extra oral environment, this barrier has the advantage of being rigid enough for placement but flexible enough to be adapted to the defect. The barrier adheres directly to dental structures; therefore sutures are not required. ${ }^{20,21}$ Chemically, the material is a polymer component that is resorbed through the process of hydrolysis. The rate of resorption is controlled and the membrane is present during critical period of healing, preventing epithelial migration and isolating the periodontal defect compartment. ${ }^{22}$ Alternatively, it can be used by placing graft material in the defect to ensure a tent like position of the membrane, applying the liquid polymer directly to the surgical site and then allowing contact with surrounding fluids, which initiates the set-up of the polymer in the firm consistency. Another bioresorbable barrier that has been developed as a membrane barrier is woven mesh barrier made of polyglactin 910 (Vicryl Periodontal Mesh, Johnson \& Johnson Consumer Products, Skillman: NJ) a copolymer of polyglycolic acid and polylactic acid with a resorption rate of 30 to 90 days. The results of several studies have questioned the use of polyglactin for guided tissue regeneration (GTR) procedures, reporting that the mesh provides an insufficient barrier because of fragmentation of the material. The integrity of the mesh is lost after 14 days, and the cervical sealing between the mesh and the adjacent tooth may not be perfect, allowing for the growth of connective tissue epithelium between the root surface and the barrier. ${ }^{23,24}$

Calcium sulfate: Medical-grade calcium sulfate, commonly known as plaster of Paris, has been used after immediate implant placement as part of a bone graft placed around the implants. Barriers composed of medical-grade calcium sulfate can be placed over bone grafts for clot stabilization and to exclude undesirable tissue (Figure $6 \& 7$ ). The advantages of this material include providing a source of calcium in the early mineralization process and aiding particle retention. ${ }^{25,26}$ This material is available in sterile kits that contain exact amounts of medical-grade calcium sulfate powder and a syringe that is prefilled with Cap Set (Lifecore Biomedical, Chaska, MN). Then mixed together, these substances create a moldable piaster that can conform to the desired shape, even in the presence of blood. Sutures are not required because this mixture is adhesive. Calcium sulfate dissolves in approximately 30 days without an inflammatory reaction, and it does not attract bacteria or support infection. ${ }^{27,28}$ The rationale for using medical-grade calcium sulfate for GTR procedures:25-30 Complete resorption within 3 to 4 weeks Biocompatibility (causes no increase in inflammation)

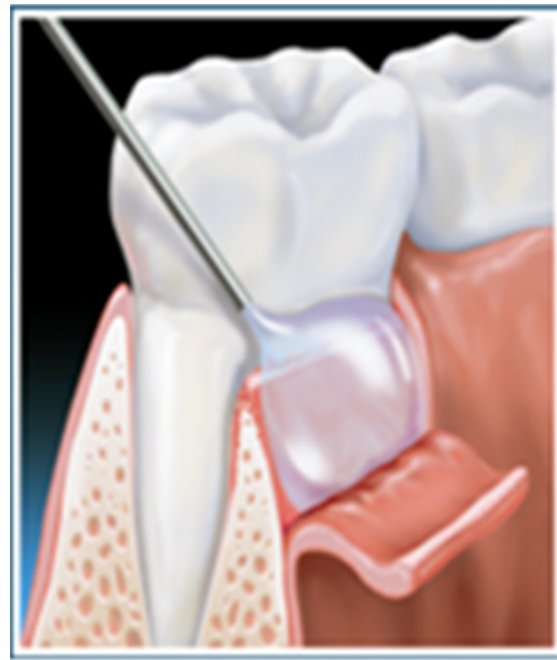

Figure 6 Synthetic liquid polymer (Atrisorb).

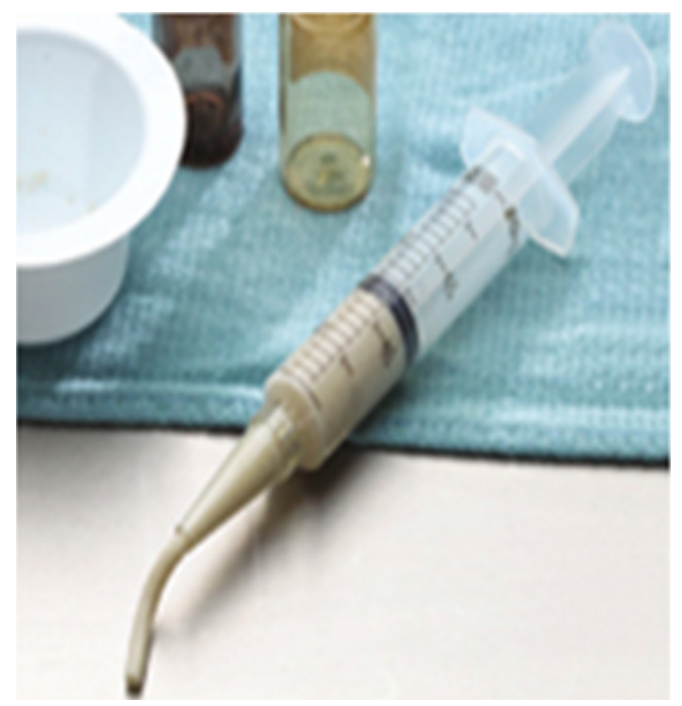

Figure 7 Medical grade Calcium sulphate.

a. Adaptability (does not need to be cut before placement)

b. Porosity (allows fluid exchange, but excludes the passage of epithelium and connective tissue)

c. Minimal postoperative discomfort

d. Clot protection during the early stages of healing

e. Soft tissue growth over exposed calcium sulfate

f. Lack of infection with material exposure

g. Less effect on cellular morphology

Acellular dermal allografts: A relatively new type of bioresorbable grafting material is cellular human cadaver skin that has been obtained from tissue banks (Alloderm, Life Cell Corp., Woodland, TX). The material has undergone a process of de-epithelialization and de-cellularization to eliminate the targets of rejection response, leaving an immunologically inert avascular connective tissue. ${ }^{17-32}$ Dermal allografts have been successfully used for the treatment of third degree burns and are currently being used as a membrane barrier, for mucogingival defects, for formation of attached gingiva, and as a biologic bandage after osseous resection.

Advantages: The use of acellular dermal allografts has several advantages because it does not contain cellular material, which eliminates the possibility of rejection because of the presence of major histocompatibility complex Class I and II antigens. In addition, the unlimited supply. ${ }^{33}$ Colour match, and thickness, as well as no degradation if primary closure is not achieved, and formation of additional attached gingiva makes this material a good choice for membrane barrier techniques.

Oxidized cellulose mesh: The oxidized material is a resorbable hemostatic dressing that converts to a gelatinous mass and incorporates the blood clot to form a membrane (Figure 8). Most of the mesh resorbed at 1 week postoperatively. ${ }^{34}$ The defects in this case demonstrated normal healing, with crevicular depths of $2 \mathrm{~mm}$ in most sites and no evidence of bleeding with gentle probing. However, the author concluded that one case report is not sufficient to make conclusions regarding the efficacy and advantages of oxidized cellular mesh for the purpose of a membrane barrier. ${ }^{35,36}$ 


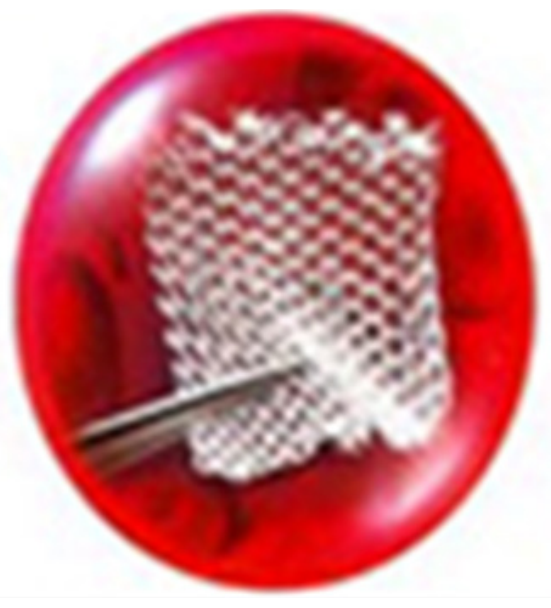

Figure 8 Oxidized Cellulose mesh.a

\section{Conclusion}

Guided Tissue Regeneration is a surgical technique employed by many clinicians. Although the term contains the word "regeneration," our histological results are usually that of a form of repair termed "new attachment." With the continuation of periodontal research and corporate alliance, one day we as a profession hope to have the ability to actually "regenerate" the periodontal apparatus including a functional periodontal ligament.

\section{Funding}

None.

\section{Acknowledgments}

None.

\section{Conflicts of interest}

The authors declare that there is no conflict of interest.

\section{References}

1. Spector M.Anorganic Bovine bone and ceramic analogs of bone material as implants to facilitate bone regeneration. Clin Plast Surg. 1994;21(3):437-444.

2. Nishibori M, Betts NJ, Salama H, et al. Short-term healing of autogenous and allogeneic bone grafts after sinus augmentation: a report of 2 cases. $J$ Periodontol. 1994;65(10):958-966.

3. Clergeau LP, Danan M, Clergeau GS, et al. Healing response to anorganic bone implantation in periodontal intrabony defects in dogs. Part I. Bone regeneration. A microradiographic study. J Periodontal. 1996;67(2):140149.

4. Triplett RG, Schow SR. Autologous bone grafts and endosseous implants: complementary techniques. J Oral Maxillofac Surg. 1996;54(4):486-494.

5. Berglundh T, Lindhe J. Healing around implants placed in bone defects treated with Bio-Oss. An experimental study in the dog. Clin Oral Implant Res. 1996;8(2):117-124.

6. Mercier P, Bellavance F, Cholewa J, et al. Long-term stability of atrophic ridges reconstructed with hydroxyapatite: A prospective study. J Oral Maxillofac Surg. 1996;54(8):960-968.

7. Zitzmann NU, Naef R, Schupbach P, et al. Immediate or delayed immediate implantation versus late implantation when using the principles of guided bone regeneration. Acta Med Dent Helv. 1996;1:221-227.
8. Zinner ID, Small SA. Sinus lift graft: Using the maxillary sinuses to support implant. J Am Dent Assoc. 1996;127(1):51-57.

9. Schmitt JM, Buck DC, John SP, et al. Comparison of porous bone mineral and biologically active glass in critical-sized defects. J Periodontol. 1997;68(11):1043-1053.

10. Johnson MW, Sullivan SM, Rohrer M, et al. Regeneration of peri-implant infrabony defects using Perioglass: A pilot study in rabbits. Int J Oral Maxillofac Implants. 1997;12(6):835-839.

11. Zamet JS, Darbar UR, Griffiths GS, et al. Particulate Bioglass as a grafting material in the treatment of periodontal infrabony defects. $J$ Clin Periodontal. 1997;24(6):410-418.

12. Shepers EJG, Ducheyne P . Bioactive glass particles of narrow size range for the treatment of oral bone defects: A 1-24 months experiment with several materials and particle sizes and size ranges. J Oral Rehab. 1997;24(3):171-181.

13. Furusawa T, Mizunuma K. Osteoconductive properties and efficacy of resorbable bioactive glass as a bone-grafting material. Implant Dent. 1997;6(2):93-101.

14. Lekholm $\mathrm{U}$, Wannfors $\mathrm{K}$, Isaksson $\mathrm{S}$, et al. Oral implants in combination with bone grafts. A 3-year retrospective multicenter study using the Brånemark implant system. Int J Oral Maxillofac Surg. 1999;28(3):181187.

15. Keller EE, Tolman DE, Eckert S. Surgical-prosthodontic reconstruction of advanced maxillary bone compromise with autogenous onlay block bone grafts and osseointegrated endosseous implants: a 12-year study of 32 consecutive patients. Int J Oral Maxillofac Implants. 1999;14(2):197209.

16. Olson JW, Dent CD, Morris HF, et al. Long-term assessment (5 to 71 months) of endosseous dental implants placed in the augmented maxillary sinus. Ann Periodontol. 2000;5(1):152-156.

17. Al Ruhaimi. Bone graft substitutes: A comparative quantitative histologic review of current osteoconductive grafting materials. Int $J$ Oral Maxillofac Implants. 2001;16(1):105-113.

18. Ashok Sethi, Thomas Kaus. Ridge augmentation using mandibular block bone grafts: Preliminary results of an ongoing prospective study. Int $J$ Oral Maxillofac Implants. 2001;16(3):378-388.

19. Tawil G, Mawla M. Sinus floor elevation using a bovine bone mineral (Bio-Oss) with or without the concomitant use of a bilayered collagen barrier (Bio-Gide): a clinical report of immediate and delayed implant placement. Int J Oral Maxillofac Implants. 2001; 16(5):713-721.

20. Hammerle CH, Jung RE, Feloutzis A. A systematic review of the survival of implants in bone sites augmented with barrier membranes (guided bone regeneration) in partially edentulous patients. J Clin Periodontol 29 Suppl . 2002;3:226-231.

21. Liversedge, Kevan W. Use of the buccal fat pad in maxillary and sinus grafting of the severely atrophic maxilla preparatory to implant reconstruction of the partially or completely edentulous patient: Technical note. Int J Oral Maxillofac Implants. 2002;17(3):424-428.

22. Guarnieri R, Bovi M. Maxillary sinus augmentation using prehardened calcium sulfate: A case report. Int $J$ Periodontics Restorative Dent. 2002;22(5):503-508.

23. Tadjoedin ES, De Lange GL, Lyaruu DM, et al. High concentrations of bioactive glass material (BioGran) vs. autogenous bone for sinus floor elevation. Clin Oral Implants Res. 2002;13(4):428-436.

24. Nathan E Carlson, Robert Roach. Platelet-Rich Plasma: Clinical Applications in Dentistry. J Am Dent Assoc. 2002;133(10): 1383-1386.

25. Block MS, Finger I, Lytle R. Human mineralized bone in extraction sites before implant placement: preliminary results. $J$ Am Dent Assoc. 2002;133(12):1631-1638. 
26. Mc Carthy C, Patel RR, Wragg PF, et al. Dental implants and onlay bone grafts in the anterior maxilla: analysis of clinical outcome. Int J Oral Maxillofac Implants. 2003;18(2):238-241.

27. Mc Carthy C, Patel RR, Wragg PF, et al. Sinus augmentation bone grafts for the provision of dental implants: report of clinical outcome. Int J Oral Maxillofac Implants. 2003;18(3):377-382.

28. Block MS, Degen M. Horizontal ridge augmentation using human mineralized particulate bone: preliminary results. J Oral Maxillofac Surg. 2004;62(9 Suppl 2):67-72.

29. Zijderveld SA, Zerbo IR, Van den Bergh JP, et al. Maxillary sinus floor augmentation using a beta-tricalcium phosphate (Cerasorb) alone compared to autogenous bone grafts. Int J Oral Maxillofac Implants. 2005;20(3):432-440.

30. Sjostrom M, Lundgren S, Nilson $\mathrm{H}$, et al. Monitoring of implant stability in grafted bone using resonance frequency analysis. A clinical study from implant placement to 6 months of loading. Int J Oral Maxillofac Surg. 2005;34(1):45-51.

31. Tetsuya N, Yutaka Y, Masakazu M, et al. Effects of bioactive glass on bone augmentation within a titanium cap in rabbit parietal bone. $J$ Periodontol. 2006;77(6):983-989.
32. Fiorellini JP, Kim DM, Nakajima Y, et al. Osseo integration of titanium implants following guided bone regeneration using expanded polytetrafluoroethylene membrane and various bone fillers. Int $J$ Periodontics Restorative Dent. 2007;27(3):287-294

33. Schlegel KA, Zimmermann R, Thorwarth $M$, et al. Sinus floor elevation using autogenous bone or bone substitute combined with platelet-rich plasma. Oral Surg Oral Med Oral Path Oral Radio Endo. 2007;104(3):e15-25.

34. Scarano A, Orsini G, Pecora G, et al. Peri-implant bone regeneration with calcium sulfate: a light and transmission electron microscopy case report. Implant Dent. 2007;16(2):195-203.

35. Barone A, Covani U. Maxillary alveolar ridge reconstruction with nonvascularized autogenous block bone: clinical results. J Oral Maxillofac Surg. 2007;65(10):2039-2046.

36. Ozkan Y, Ozcan M, Varol A, et al. Resonance frequency analysis assessment of implant stability in labial onlay grafted posterior mandibles: a pilot clinical study. Int J Oral Maxillofac Implants. 2007;22(2):235-242. 